\title{
Chemo-mechanical coupling constitutive model for chalk considering chalk-fluid physicochemical interaction
}

\author{
T. MA* C. WEI†+, P. CHEN† and W. LI†
}

\begin{abstract}
Chalk shows a pronounced water-weakening effect, which can be attributed to the microscopic physicochemical interactions between the pore fluid and the chalk matrix. In this paper a conceptual elastoplastic model is developed for describing the chemo-mechanical behaviour of chalk based on the framework of the modified Cam Clay model. Central to the model is the concept of intergranular stresses, introduced as the substitute for Terzaghi's effective stress to describe the chalk behaviour. In this context, the microscopic physicochemical interactions are characterised by introducing a macroscopic surface force potential. The composition and significance of pore water pressure are analysed, and the intergranular stress tensor is explicitly defined. To address the hardening effect of the microscopic physicochemical interactions, the preconsolidation pressure function is modified by introducing the intrinsic intergranular pressure as an additional hardening variable that accounts solely for the chalk-fluid interaction. It is shown that the proposed concept of intergranular stresses can address the effects of osmosis, adsorption and capillarity on the chalk behaviour in a consistent and systematic way. Comparisons between the theoretical simulations and experimental results demonstrate that the proposed model is capable of capturing the main features of the chemo-mechanical behaviour of chalk saturated with an individual or two (miscible or immiscible) fluids.
\end{abstract}

KEYWORDS: chalk; chemical properties; constitutive relations; partial saturation

\section{INTRODUCTION}

Seawater injection used to be an important approach to re-pressurising the oil reservoirs in the North Sea, in order to alleviate the seabed subsidence problem induced by oil production. This method also proved to have great potential for enhancing oil recovery. Unfortunately, however, significant enhanced reservoir compaction and seabed subsidence could occur during the injection of seawater into some oil reservoirs (Keszthelyi et al., 2016). It has been well recognised that the problem can be attributed to the water-weakening effect of chalk, which is a constituent material of the reservoirs (e.g. Newman, 1983; Risnes et al., 2003; Keszthelyi et al., 2016). In the north part of the North Sea, many oil reservoirs are mainly composed of chalk, which is a type of carbonate rock, built up of the fragments of calcite skeletons originating from planktonic algae called coccolithophorids (Risnes et al., 2003). Because of its unique lithological composition and structural features, the chalk material generally has a rather open structure, with a porosity ranging from 40 to $50 \%$. In addition, the small size of the individual grains also results in a large specific surface area of chalk (about $2 \mathrm{~m}^{2} / \mathrm{g}$ ).

Manuscript received 1 May 2017; revised manuscript accepted 12 June 2018. Published online ahead of print 11 July 2018.

Discussion on this paper closes on 1 September 2019, for further details see p. ii.

Published with permission by the ICE under the CC-BY 4.0 license. (http://creativecommons.org/licenses/by/4.0/)

* State Key Laboratory of Geomechanics and Geotechnical Engineering, Institute of Rock and Soil Mechanics, Chinese Academy of Sciences, Wuhan, Hubei, P. R. China (Orcid:0000-0001-7374-3268).

$\uparrow$ State Key Laboratory of Geomechanics and Geotechnical Engineering, Institute of Rock and Soil Mechanics, Chinese Academy of Sciences, Wuhan, Hubei, P. R. China.

\$ College of Civil and Architectural Engineering, Guilin University of Technology, Guilin, Guangxi, P. R. China.
In the past three decades, considerable research efforts have been made to study the mechanical behaviour of chalk. In particular, an extended experimental testing programme has been performed to investigate the interaction between water and chalk (Delage et al., 1996; Risnes \& Flaageng, 1999; Hellmann et al., 2002; Risnes et al., 2003; Taibi et al., 2009; Omdal et al., 2010; Lawrence et al., 2013). It has been well recognised that a water-saturated chalk is mechanically weaker than a dry or oil-saturated chalk (Duperret et al., 2005), and skeletal deformation occurs whenever the chalk is exposed to water (Newman, 1983; Heggheim et al., 2005; Risnes et al., 2005; Madland et al., 2006). Specifically, the mechanical parameters of chalk such as the Young's and bulk moduli, pore collapse yield stress and cohesive intercept decrease with the increase of water saturation, whereas other parameters (including Poisson's ratio, plastic volumetric hardening modulus and friction angle) remain practically constant (Papamichos et al., 1997; Talesnick et al., 2001).

Several mechanisms have been proposed to explain the water-weakening effect of chalk. One of the most-cited mechanisms is associated with intergranular pressure solution. Hellmann et al. (2002) discussed in detail such a mechanism and presented a thermodynamic model of the pressure solution process. It is shown, however, that although the pressure solution is a time-dependent process (Risnes et al., 2005), the solubility of calcite in water is generally too low to suggest that such a mechanism is dominant (Stumm \& Moyan, 1981). The capillarity effect provides another explanation for the water-weakening effect of chalk (Delage et al., 1996). It is suggested that the influence of unsaturation on pure chalk of a high porosity is similar to that on partially saturated soils, and the water-oil menisci can pull the grains together, increasing the cohesion force of the material. As a consequence, when seawater is injected into the chalk pores, the capillary menisci collapse and the chalk becomes weaker. The capillary effect has also been introduced 
by several other researchers to explain the reduction of chalk strength with an increase of water saturation (Delage et al., 1996; Papamichos et al., 1997; Risnes et al., 2003, 2005).

Although the capillary effect can partly account for the water weakening of chalk, it is clearly not the only mechanism activated in the pores during water injection. Lord et al. (1998) performed thermal decomposition-mass spectrometry analyses on reservoir chalks and found that dry chalks did not contain sufficient adsorbed water to support water-oil menisci and activate the capillary mechanism. In addition, Risnes \& Flaageng (1999) conducted a series of experiments on chalk samples saturated with water-ethylene glycol mixtures, which are completely miscible. These authors showed that the water-saturated chalk was considerably weaker than the chalk saturated by methanol, although the capillary force was absent. Thus, it is clear that the capillary mechanism alone (i.e. capillary menisci collapses) is insufficient to explain the waterweakening effect of chalk. Based on experimental results, Risnes et al. (2003) pointed out that the activity of water was a key parameter in water weakening of chalk, and the intensity of the water-weakening effect depended upon the strength of adsorption of fluid molecules onto the calcite surface.

In addition to capillary forces, other physicochemical interactions also exist between the chalk matrix and the saturating fluid (De Gennaro et al., 2004). In general, a chalk material is electrically charged, implying that an electric double layer can develop around chalk grains. In fact, a strong interaction of an electrostatic nature has been observed in the zeta potential of chalk samples saturated with different fluids (Risnes et al., 2003). The overlap of the double layer may create repulsive forces when two neighbouring grains are close enough to each other (Gonçalvès et al., 2010). In addition, owing to the electrically charged nature of chalk material, disjoining pressure can develop in the pore water in the interstices between two chalk grains. Hiorth et al. (2010) calculated the surface charge and the disjoining pressure for different aqueous solutions. Megawati et al. (2013) pointed out that the reduction of yield stress associated with the water weakening of chalk could be explained using the concept of the disjoining pressure.

Mechanically, high-porosity chalks behave like frictional materials, which fail in a shear mode at low mean stresses. However, the open structure of rock matrix causes another failure mechanism, often referred to as pore collapse (Halleux et al., 1990; Schroeder \& Shao, 1996; Homand \& Shao, 2000a, 2000b; Collin et al., 2002; De Gennaro et al., 2004). More recently, a number of constitutive models have been proposed for describing the mechanical behaviour of porous chalks. Most of them were based on the framework of the classic elastoplastic models used in soil mechanics. Homand \& Shao (2000a, 2000b) developed an elastoplastic model with two yield surfaces to describe the chalk behaviour, which treated the water-saturated chalk and oilsaturated chalk, separately. This model included two sets of material parameters, corresponding to the two different saturating fluids, respectively, and introduced an additional plastic potential to describe the water-induced plastic deformation. Following a different approach, some constitutive models were developed by considering of the effect of capillary pressure (e.g. Schroeder et al., 1998). In particular, in the European Commission (EC) research programme PASAChalk, a constitutive model was derived from the Barcelona basic model (Alonso et al., 1990) of unsaturated soils, in which the matric suction was introduced to account for the water sensitivity of porous chalk (Collin et al., 2002;
De Gennaro et al., 2003). These models considered the capillary effect as the only water-weakening mechanism of chalk, and excluded the effect of the physicochemical interactions between the chalk matrix and the saturating fluid. The model by Papamichos et al. (1997) uses the degree of water saturation as an internal variable to describe the water-weakening effect (on the stiffness and strength) of chalk in a phenomenological way. In this model, all the physicochemical effects are lumped into an internal variable; that is, the degree of saturation.

The paper is organised as follows. The capillary and physicochemical effects are first characterised, and an explicit expression for the surface force potential is developed; then the concepts of pore water pressure, the generalised osmotic pressure and the intergranular stress are explicitly defined. In this context, a chemicalmechanical coupling constitutive model is developed for describing the mechanical behaviour of chalk. The proposed model accounts for osmosis, adsorption and capillarity in a consistent and systematic way, providing better understanding of the mechanisms behind the chalk-water interactions.

\section{CHARACTERISATION OF CHALK-FLUID INTERACTIONS}

Physicochemical interactions between pore water and chalk matrix

Chalk matrix is negatively charged at natural $\mathrm{pH}$ values, as inferred from the negative of zeta potential (Risnes et al., 2003). Thus it is expected that significant physicochemical interactions occur among mineral surfaces, water dipoles and electrically charged species. These interactions make the pore solution behave differently from its free bulk state, in that the former is under the influence of surface forces (Nitao \& Bear, 1996). These surface forces include the surface tension on the interface between two immiscible bulk phases coexisting in the pores, and the adsorptive forces stemming from the physicochemical interactions among different bulk phases, including electrostatic forces, van der Waals attraction, double-layer repulsion, and so on (Mitchell \& Soga, 2005). All these interactions can modify the potential energy of pore fluids, so that a pore fluid has a potential energy different from its counterpart free of the surface forces under the same thermodynamic condition.

To characterise the microscopic interactions associated with interfaces, Wei (2014) showed that the free energy of the pore solution can be decomposed into two components, namely, the free energy of the pore solution free of surface forces and the surface force potential accounting for the surface forces. The surface force potential $\Omega^{l}$ is defined as the negative specific work done against the surface forces during the movement of an infinitesimal amount of fluid, in a thermodynamically reversible manner, from a reservoir to the chalk at the same state (characterised by temperature $T$, the mass density of the pore solution $\rho^{l}$ and mass fraction of species $C^{l_{i}}$. Potential $\Omega^{l}$ has two contributions, namely, capillarity and adsorption, which can be specified as a function of temperature $T$, liquid volume fraction $n^{l}$ and concentration $C^{l_{i}}$. Explicitly, $\Omega^{l}$ is given by

$$
n^{l} \rho^{l} \Omega^{l}=\phi \rho^{l} \Omega_{0}^{l}+\int_{n^{l}}^{\phi}\left(s_{\mathrm{M}}-\Pi_{\mathrm{D}}\right) \mathrm{d} n^{l}
$$

or equivalently

$$
S_{\mathrm{r}} \rho^{l} \Omega^{l}=\rho^{l} \Omega_{0}^{l}+\int_{S_{\mathrm{r}}}^{1}\left(s_{\mathrm{M}}-\Pi_{\mathrm{D}}\right) \mathrm{d} S_{\mathrm{r}}
$$


where $n^{l}$ is the volume fraction of the liquid phase, equal to the porosity $\phi$ multiplied by the degree of water saturation $S_{\mathrm{r}}$; $\rho^{l}$ is the mass density of the pore solution, and for a dilute solution, it approximately equals to $\rho_{\oplus}^{l_{\mathrm{H} 2 \mathrm{O}}}\left(=1.0 \mathrm{~g} / \mathrm{cm}^{3}\right)$, which is the mass density of pure water (for simplicity, $\rho$ and $\rho_{\oplus}^{l_{\mathrm{H} 2 O}}$ will be used interchangeably in the following); $s_{\mathrm{M}}\left(=p^{g}-p_{\mathrm{W}}{ }^{l}\right)$ is the matric suction, where $p^{g}$ is the pore air pressure or oil pressure and $p_{\mathrm{W}}^{l}$ is the measured water pressure (i.e. the pressure of the equilibrium solution, as defined later); $\Omega_{0}^{l}$ is the surface force potential at full saturation; and $\Pi_{\mathrm{D}}$ is the Donnan osmotic pressure.

To evaluate the pore water pressure in a chalk, it is instructive to introduce the concept of 'equilibrium solution', which is defined as the chalk solution (in a reservoir) in contact, and in equilibrium, with the pore water in the chalk. Owing to the electrically charged nature of chalk, the equilibrium solution is different from the pore water in that they have different concentrations, although both may have the same components (the semipermeable membrane effect). This phenomenon is usually called Donnan's effect (Mitchell \& Soga, 2005), as schematically shown in Fig. 1(a). Donnan's effect can induce an osmotic pressure between the equilibrium solution and the pore water, that is, Donnan osmotic pressure. It can be shown that the Donnan osmotic pressure is given by (Wei, 2014)

$$
\Pi_{\mathrm{D}}=\frac{R T \rho_{\oplus}^{l_{\mathrm{H}_{2} \mathrm{O}}}}{M_{\mathrm{H}_{2} \mathrm{O}}} \ln \left(\frac{a_{\mathrm{R}}^{l_{\mathrm{H}_{2} \mathrm{O}}}}{a_{\mathrm{P}}^{l_{\mathrm{H}_{2} \mathrm{O}}}}\right)
$$

where $R$ is the universal gas constant; $T$ is the Kelvin temperature; $M_{\mathrm{H}_{2} \mathrm{O}}$ is the molar mass of water; and $a_{\mathrm{R} 2 \mathrm{O}}^{l_{\mathrm{H}}}$ and $a_{\mathrm{P}}^{l_{\mathrm{H} 2}}$ are the activities of the solvent (i.e. water molecules) in the equilibrium solution and the chalk pores, respectively. Equation (3) implies that $\Pi_{D}$ depends on the fixed charge density $c_{\text {fix }}$, the concentration of the equilibrium solution $c_{0}$ and the volume fraction of liquid phase $n^{l}$, as well as the nature of chalk-water interaction. Figures 1(b) and 1(c) schematically illustrate the variations of $\Pi_{\mathrm{D}}$ with $c_{\mathrm{fix}}$ and $c_{0}$, respectively. A quantitative demonstration of the relationship between $\Pi_{\mathrm{D}}, c_{0}, c_{\text {fix }}$ and $n^{l}$ for a clayey soil saturated with sodium chloride solution can be found in Ma et al. (2016).

Equations (1) or (2) imply that $\Omega^{l}$ can be determined using the water retention curve, provided that the functional dependence of $\Pi_{\mathrm{D}}$ on $n^{l}$ (or $S_{\mathrm{r}}$ ) is given. For oil-saturated chalk, the oil-chalk interaction is generally weak, so that $\Omega^{l}$ is vanishingly small. However, when the chalk is saturated with water, the strong water-chalk interaction makes the value of $\Omega^{l}$ significantly different from that of the oilsaturated chalk.

\section{Intergranular stress}

Traditionally, the effect of physicochemical forces has been excluded in Terzaghi's effective stress, although it can generally exert significant controls over the deformation and strength of clayey soils (Sridharan \& Venkatappa Rao, 1973). These physicochemical forces exist in both saturated and unsaturated states. The true effective stress should be able to account for the effects of both the external forces and the surface forces associated with microscopic solid-fluid interactions and surface tensions (Lu \& Likos, 2006).

Based on the requirements for thermodynamic equilibrium, it has been shown (Wei, 2014) that the true water pressure, $p^{l}$, can be decomposed into (Fig. 2)

$$
p^{l}=p_{\mathrm{W}}^{l}+\Pi
$$

where $p_{\mathrm{W}}^{l}$ is the pressure of the equilibrium solution; $\Pi$ is the generalised osmotic pressure, which accounts for the

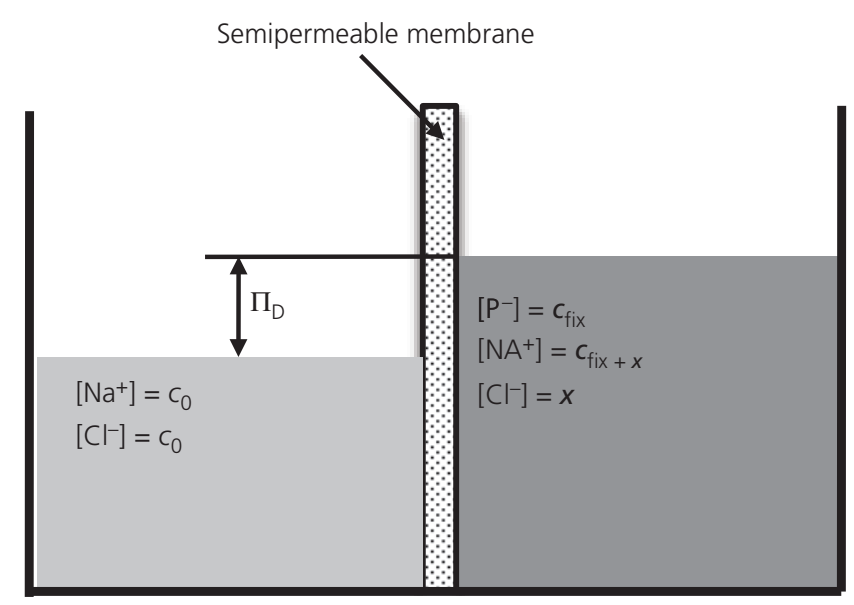

(a)

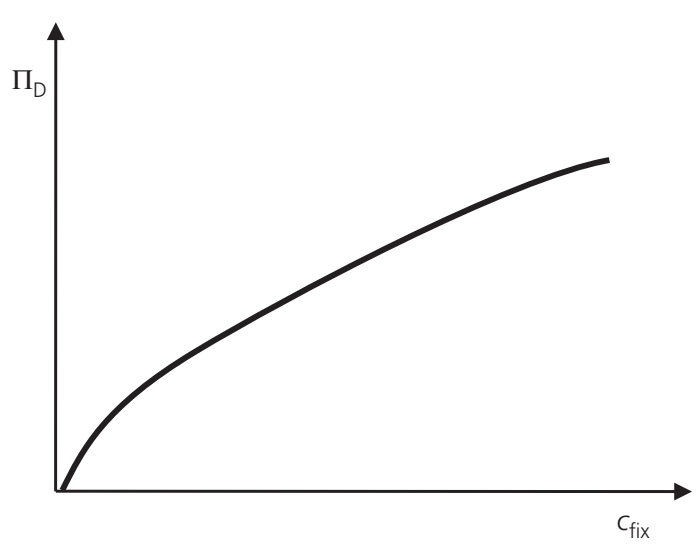

(b)

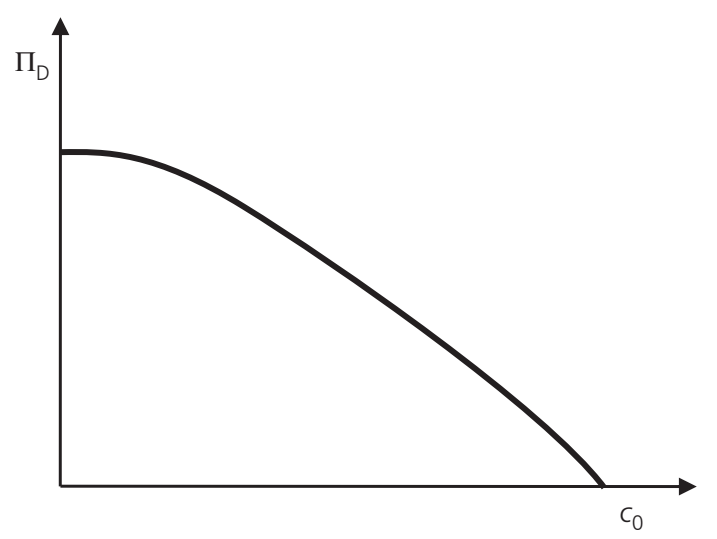

(c)

Fig. 1. (a) Schematic illustration of Donnan's effect, where $x$ depends on the fixed charge density $c_{\text {fix }}$, and the concentration of the equilibrium solution $c_{0}$; (b) relationship between the Donnan osmotic pressure and the fixed charge density $c_{\text {fix }}$; (c) relationship between the Donnan osmotic pressure and the concentration of the equilibrium solution $c_{0}$

physicochemical interactions between the pore water and the solid matrix; and

$$
\Pi=\Pi_{\mathrm{D}}-\rho_{\oplus}^{l_{\mathrm{H}_{2} \mathrm{O}} \mathrm{O}} \Omega^{l}
$$

Clearly, the generalised osmotic pressure includes two contributions: one is due to the Donnan osmosis, and the other is associated with the surface forces stemming from the microscopic solid-fluid interactions and surface tensions. 


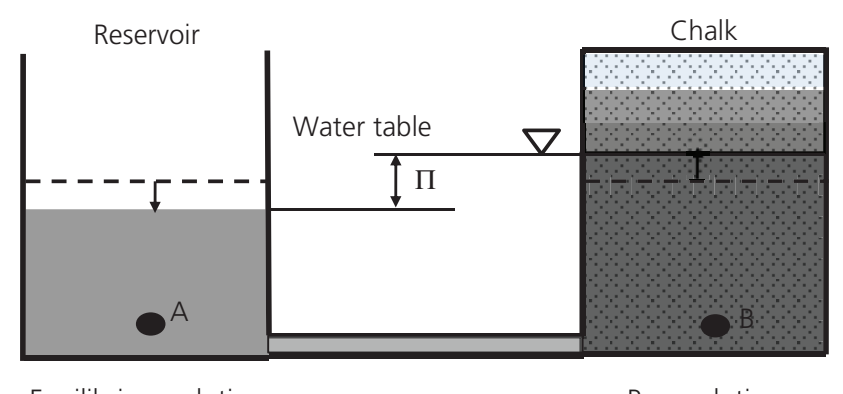

Equilibrium solution

Pore solution

Fig. 2. Schematic illustration of the generalised osmotic pressure. The reservoir contains an equilibrium solution, which is in contact and in equilibrium with the chalk. Owing to the electrically charged nature of the chalk, Donnan osmosis and adsorptive phenomena appear in the chalk, and a generalised osmotic pressure $\Pi$ is generated

Based on the true pore pressure as given by equation (4), an explicit formulation is developed for the intergranular stress tensor, that is

$$
\boldsymbol{\sigma}^{\prime \prime}=\boldsymbol{\sigma}-p^{g} \mathbf{1}+n^{l}\left(s_{\mathrm{M}}-\Pi\right) \mathbf{1}
$$

where $\boldsymbol{\sigma}^{\prime \prime}$ is the intergranular stress tensor; $\boldsymbol{\sigma}$ is the total stress tensor; and $\mathbf{1}$ is the second-order unit tensor, with components $\delta_{i j}$. At full saturation, $\Pi=\Pi_{\mathrm{D}}-\rho^{l} \Omega^{l}=s_{\mathrm{M}}=\mathrm{AEV}$ and $p^{g}=p_{\mathrm{W}}{ }^{l}+\mathrm{AEV}$, where AEV is the air entry value, so that $\boldsymbol{\sigma}^{\prime \prime}=\boldsymbol{\sigma}-p_{\mathrm{W}}^{l} \mathbf{1}-\left(\Pi_{\mathrm{D}}-\rho^{l} \Omega^{l}\right) \boldsymbol{1}=\boldsymbol{\sigma}-p_{\mathrm{W}}^{l} \mathbf{1}-\Pi \mathbf{1}$, or $\boldsymbol{\sigma}^{\prime \prime}=\boldsymbol{\sigma}^{\prime}-\Pi \mathbf{1}$, where $\boldsymbol{\sigma}^{\prime}$ is Terzaghi's effective stress and given by $\boldsymbol{\sigma}^{\prime}=\boldsymbol{\sigma}-p_{\mathrm{W}}^{l} \mathbf{1}$. From the above derivations, it is clear that the intergranular stress equation of unsaturated soil can smoothly convert to that of saturated soil as the soil switches from a partially saturated state to full saturation. A detailed derivation of equation (6) can be found in the reference Wei (2014). In Terzaghi's effective stress formulation, $\Pi$ is dropped out, implying that the physicochemical effect has been excluded.

In the following, the proposed intergranular stresses are used as the substitute for Terzaghi's effective stress to describe the chalk behaviour. When the chalk is saturated with oil (or glycol), there is no Donnan effect, so that $\Pi_{D}=0$. Owing to the weak interaction between chalk and oil, the contribution of the surface forces in the oil-saturated chalk can be neglected. Hence, the generalised osmotic pressure of the oil-saturated chalk is zero, that is, $\Pi=0$. For the watersaturated chalk, the chalk-water interaction is pronounced and the value of $\Pi$ is non-zero. Therefore, the (compressive) intergranular stress of oil-saturated chalk is larger than that of water-saturated chalk, rendering the oil- (or glycol-) saturated sample considerably stronger than the watersaturated sample. Because the generalised osmotic pressure depends upon the temperature, the intergranular stress is also temperature dependent. In general, the intergranular stress decreases, as the temperature increases, so that the waterweakening effect becomes more pronounced at higher temperature.

Owing to the small size of chalk grains, a very small amount of water could be sufficient to coat completely all of the chalk grains, so that the water-weakening mechanism in the chalk is activated (Lord et al., 1998). This can be explained by the intergranular stress formulation given above. Indeed, it has been shown that the magnitudes of intergranular stress at very low water saturation (say several per cent) and at high saturation are quite similar (Wei, 2014). Noticeably, sufficient experimental evidence has shown that the process of water weakening is largely reversible. When water-saturated chalk is dried, it more or less regains its initial strength, indicating that the capillarity and physicochemical interactions are the most important mechanisms for the water-weakening effect.

\section{CONSTITUTIVE MODEL}

For simplicity, the time-dependent effect is excluded and only infinitesimal deformation is considered in the following. It is also assumed that

(a) the fixed charge density $c_{\text {fix }}$, which is defined as the total number of fixed charges per unit mass of the solid matrix, remains constant

(b) the solutions are ideal, so that the activity of a species is equal to its molar faction

(c) plastic pore collapse and plastic shear strain are independent properties

(d) in addition, the de-cementation effect, which may result in the softening behaviour of chalk at low confining pressure, is not taken into account in the cohesion.

As usually assumed in the theory of elastoplasticity, the total strain increment can be additively decomposed into an elastic part and a plastic part, that is

$$
\mathrm{d} \varepsilon_{i j}=\mathrm{d} \varepsilon_{i j}^{\mathrm{e}}+\mathrm{d} \varepsilon_{i j}^{\mathrm{p}}
$$

The elastic behaviour is assumed to be isotropic, and described by

$$
\mathrm{d} \varepsilon_{i j}^{\mathrm{e}}=\frac{1+v}{E} \mathrm{~d} \sigma_{i j}^{\prime \prime}-\frac{v}{E} \mathrm{~d} \sigma_{k k}^{\prime \prime} \delta_{i j}
$$

where $\sigma_{i j}^{\prime \prime}$ are components of the intergranular stress tensor; $E$ and $v$ are the elastic parameters, that is, Young's modulus and Poisson's ratio, respectively. In general, the elastic properties of chalks depend upon the degree of fluid saturation and the type of saturating fluid. For simplicity, however, $E$ and $v$ are assumed constant in the following.

\section{Yielding and hardening}

The stress-strain relationship is developed by generalising the modified Cam Clay model (Roscoe \& Burland, 1968), in which the yield function is given by

$$
f=q^{2}+M^{2}\left(p^{\prime \prime}+c / M\right)\left(p^{\prime \prime}-p_{\mathrm{c}}\right)
$$

where $p^{\prime \prime}$ is the mean intergranular pressure, that is, $p^{\prime \prime}=$ $\sigma_{k k}^{\prime \prime} / 3 ; q$ is the deviatoric intergranular stress, that is, $q=$ $\sqrt{3 J_{2}}=\sqrt{(3 / 2) s_{i j} s_{i j}}$ and $s_{i j}=\sigma_{i j}^{\prime \prime}-p^{\prime \prime} \delta_{i j} ; M$ is the slope of the critical state line; $c$ is the apparent cohesion, that is, the shear strength with zero normal stress on the shear plane; and $p_{\mathrm{c}}$ is the preconsolidation pressure. Experimental observations have revealed that the preconsolidation pressure or the yielding pressure increases as matric suction increases (EC, 2004). Hence, the yield surface evolves as $p_{\mathrm{c}}$ varies. The yield and failure diagram is schematically illustrated in Fig. 3, showing that the oil-saturated sample is much stronger than the water-saturated sample.

In the modified Cam Clay model, the preconsolidation pressure, $p_{\mathrm{c}}$, is assumed to depend upon the plastic volumetric strain, $\varepsilon_{\mathrm{v}}^{\mathrm{p}}$. Apparently, such a hardening rule is insufficient when modelling the hardening behaviour of chalk materials. As discussed above, owing to the effects of capillarity and chalk-water interactions, there exist additional intergranular stresses in the chalk, which can significantly enhance the hardening effect of the solid matrix. To address these effects, one can introduce the intrinsic intergranular pressure, which is equal to the intergranular stress when the total stress is zero and the air pressure equals 


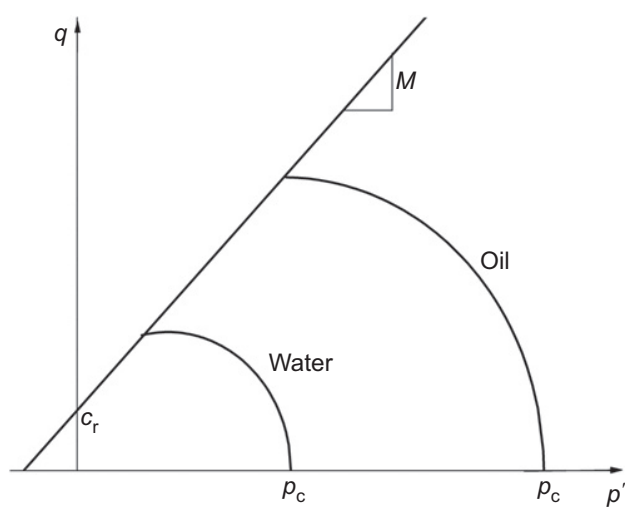

Fig. 3. Schematic representation of the yielding surface and failure line of chalk saturated by oil and water

the atmospheric pressure. By its very definition, the intrinsic intergranular stress is $p_{i}=n^{l}\left(s_{\mathrm{M}}-\Pi\right)$. Clearly, $p_{i}$ can be considered as an internal variable, which accounts for the hardening effects of capillarity and chalk-water interaction. Based on the above remarks, it is proposed that

$$
p_{\mathrm{c}}=p_{\mathrm{c} 0}\left(\varepsilon_{\mathrm{v}}^{\mathrm{p}}, \Pi_{0}\right) h\left(p_{i}\right)
$$

where $p_{\mathrm{c} 0}$ is the preconsolidation pressure when the chalk is fully saturated with water, which is a function of plastic volumetric strain $\varepsilon_{\mathrm{v}}^{\mathrm{p}}$ and the initial generalised osmotic pressure of the fully saturated sample without capillary effect $\Pi_{0}$, that is, $\Pi_{0}=\Pi_{\mathrm{D}}-\rho_{\oplus}^{\mathrm{H}_{2} \mathrm{O}} \Omega_{0}^{l}$. The latter (i.e. $\Pi_{0}$ ) is used to describe the physicochemical effect on the mechanical behaviour of the fully saturated chalk. Experimental results show that $p_{\mathrm{c} 0}$ increases as $\Pi_{0}$ decreases. For the same chalk matrix, the water-saturated sample has a larger value of $\Pi_{0}$ than the oil-saturated sample. Hence, it is assumed that

$$
p_{\mathrm{c} 0}\left(\varepsilon_{\mathrm{v}}^{\mathrm{p}}, \Pi_{0}\right)=p_{\mathrm{c} 0}^{*} \exp \left(\frac{v \varepsilon_{\mathrm{v}}^{\mathrm{p}}}{\lambda-\kappa}\right) \exp \left(-\beta \Pi_{0}\right)
$$

where $p_{\mathrm{c} 0}^{*}$ is the initial preconsolidation pressure of chalk; $v$ is the specific volume, $v=1+e$, and $e$ the void ratio; $\lambda$ and $\kappa$ are the slopes of the normal consolidation line and the unloading-reloading line on the $v-\ln p^{\prime \prime}$ plane, respectively; and $\beta$ is a positive parameter, representing the intensity of the effect of the physicochemical interactions on the hardening behaviour. Experimental results indicate that both $\kappa$ and $\lambda$ depend very slightly on the suction and the type of the saturating fluid (Homand \& Shao, 2000a, 2000b; EC, 2004). For simplicity, it is assumed that both $\lambda$ and $\kappa$ remain constant. Noticeably, $\Pi_{0}$ vanishes when the chalk is dry or fully saturated with an oil.

When the chalk becomes partially saturated, $p_{\mathrm{c}}$ increases as the saturation decreases. As a hardening variable, the intrinsic granular pressure, $p_{i}$, can be used to represent the effects of both capillarity and chalk-water interactions. For simplicity, the hardening function can be assumed as

$$
h\left(p_{i}\right)=\exp \left(\beta p_{i}\right)
$$

At full saturation, $p_{i}=0$ and $h=1$, so that the proposed constitutive model reduces into its fully saturated counterpart.

\section{Critical state line}

Based on the principle of Terzaghi's effective stress, both the critical state and the failure lines are unique for the chalk saturated with different fluids, provided that these lines are presented using the proposed intergranular stress. Previous experimental results indicate that the apparent cohesion of chalk can be significantly influenced by the composition and concentration of the pore fluid, although its friction angle remains practically constant (Taibi et al., 2009). Thus it is proposed herein that

$$
q=M p^{\prime \prime}+c_{\mathrm{r}}
$$

where $M$ remains constant and $c_{\mathrm{r}}$ is the apparent cohesion of the chalk at the reference state. The reference state can be chosen as the state of the chalk when it is dry or oil-saturated, at which the generalised osmotic pressure is zero, that is, $\Pi_{0}=0$.

Remarkably, due to the uniqueness of the critical state line, equation (13) provides a constraint which can be used to evaluate the generalised osmotic pressure, П. To illustrate this, one may present the critical state line on the $p^{\prime} \sim q$ plane (Fig. 4), where $p^{\prime}=\sigma_{k k}^{\prime} / 3$ and $\sigma_{i j}^{\prime}$ are the components of Terzaghi's effective stress tensor. Explicitly, one can write the critical state line as: $q=M p^{\prime}+c$, for the water-saturated chalk, and $q=M p^{\prime}+c_{\mathrm{r}}$, for the oil-saturated or dry chalk. Because $\Pi=0$ for the oil-saturated chalk, the uniqueness of the critical line requires that $\Pi=\Delta c / M$, where $\Delta c=c_{\mathrm{r}}-c$.

\section{Plastic flow rules}

An associated flow rule is adopted to describe the evolution of the plastic strain. That is, the incremental plastic strains are given by

$$
\mathrm{d} \varepsilon_{i j}^{\mathrm{p}}=\mathrm{d} \lambda \frac{\partial f}{\partial \sigma_{i j}^{\prime \prime}}
$$

where $\mathrm{d} \lambda$ is the plastic multiplier, which can be determined by way of the consistency condition.

\section{Description of water retention properties}

The water retention characteristics of chalk are represented by the water retention characteristic curves that represents the relationship between the degree of saturation $S_{\mathrm{r}}$ and the matric suction $s_{\mathrm{M}}$. In general, this relationship shows hysteresis behaviour during wetting/drying cycles, which can be taken into account in a straightforward manner (Ma et al., 2016). For clarity, however, the hysteresis is neglected here, and van Genuchten's model (van Genuchten, 1980) is adopted to describe the one-to-one relationship between the degree of saturation and matric suction, namely

$$
S_{\mathrm{r}}=\left[\frac{1}{1+\left(s_{\mathrm{M}} / \alpha\right)^{n}}\right]^{1-(1 / n)}
$$

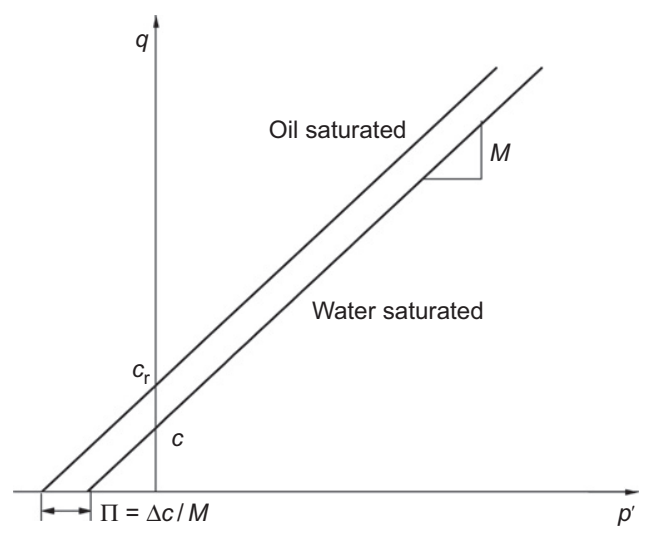

Fig. 4. Schematic representation of the critical state lines for oil-saturated and water-saturated samples 
where $\alpha$ and $n$ are material parameters, related to the air entry value and the slope of retention curve, respectively.

\section{Evaluation of constitutive parameters}

In the constitutive model, both the capillary effect and the physicochemical chalk-fluid interaction are taken into account. These effects can be considered in a systematic and consistent way by using the intergranular stress, which is used as the stress state variable. The proposed model can smoothly transit between two extreme states, that is, the water-saturated and the oil-saturated (or dry) states. In the intermediate state between the two extreme states, the proposed model can describe the behaviour of the partially saturated chalks with any degree of water saturation. In addition, the proposed model is capable of simulating the mechanical behaviour of samples saturated with brines. Remarkably, in all the simulations, the proposed model includes a unique set of constitutive parameters (although they assume different values for different materials).

The constitutive parameters can be divided into the following three groups

(a) mechanical parameters, including $E, v, \lambda, \kappa, M, c_{\mathrm{r}}$ and $p_{\mathrm{c} 0}^{*}$

(b) water retention characteristic parameters, including $n, \alpha$ and $n^{l}$

(c) physicochemical parameters, including $c_{\mathrm{fix}}, \Omega_{0}^{l}$ and $\beta$.

Compared with the modified Cam Clay model, the new model explicitly considers the effect of the reference cohesion, $c_{\mathrm{r}}$, which is the initial cohesion of the oil-saturated chalk $\left(\Pi_{0}=0\right)$. In the simulation, all the mechanical parameters are assumed constant, that is, independent of the saturating fluid, and they can be determined in the same way as those in the modified Cam Clay model. Parameter $c_{\mathrm{r}}$ can be obtained by determining the intersection of the critical state line of the oil-saturated chalk with the $q$ axis. The retention characteristic parameters can be determined by fitting van Genuchten's equation with experimental data.

Among the physicochemical parameters, $c_{\text {fix }}$ is related to the cation exchange capacity (CEC) of a chalk, $c_{\text {fix }}=10 \mathrm{CEC} \times \rho_{\mathrm{d}}$, where $\rho_{\mathrm{d}}$ is the dry density of the sample $\left(\mathrm{g} / \mathrm{cm}^{3}\right)$. For porous media saturated with a dilute solution of a simple salt (say a dilute sodium chloride solution), if $c_{\text {fix }}$ is given, the concentrations of species can be calculated by Donnan's theory (see the Appendix). In this case, the solution is assumed ideal, so that the activity of a species in the solution is equal to its molar fraction (denoted as $m^{l_{\alpha}}$ ). In particular, for a dilute sodium chloride solution, $a_{\mathrm{A}}^{l_{\mathrm{H}_{2} \mathrm{O}}}=m_{\mathrm{A}}^{l_{\mathrm{H}_{2} \mathrm{O}}} \approx 1-2 c_{0}$ and $a^{l_{\mathrm{H}_{2} \mathrm{O}}}=m^{l_{\mathrm{H}_{2} \mathrm{O}}} \approx 1-c^{l_{\mathrm{Na}^{+}}}-c^{l_{\mathrm{Cl}^{-}}}$, where $c^{l_{\alpha}}$ is the molar concentration of species $\alpha$, and $c^{l_{\mathrm{Na}+}}=c^{l_{\mathrm{Cl}-}}=c_{0}$ in the equilibrium solution. Then Donnan's osmotic pressure $\Pi_{D}$ is calculated from equation (3).

To evaluate $\Omega_{0}^{l}$, one first notes that $\rho_{\oplus}^{l_{\mathrm{H}_{2} \mathrm{O}}} \Omega_{0}^{l}=\Pi_{\mathrm{D}}-s_{\mathrm{M}}$ at full saturation (Wei, 2014). At the full water saturation, $s_{\mathrm{M}}$ is simply equal to the AEV, which can be obtained from the water retention curve. Then $\Omega_{0}^{l}$ can be calculated by combining AEV and $\Pi_{\mathrm{D}}$. Given $\Pi_{\mathrm{D}}$ and $\Omega_{0}^{l}$ as well as $s_{\mathrm{M}}\left(S_{\mathrm{r}}\right)$, the surface force potential can be calculated from equation (2). Finally, the generalised osmotic pressure $\Pi$ can be calculated from equation (5).

Parameter $\beta$ controls the rate of the increase of the chalk yield pressure with the internal pressure, which can be determined by fitting equation (10) with the experimental data about the variation of the preconsolidation pressure with the internal pressure.

\section{MODEL PERFORMANCE}

\section{Uniqueness of failure line}

In this section, the uniqueness of the failure line is examined by virtue of the proposed intergranular stress. To address the problem of chalk-fluid interactions, Risnes et al. (2003) performed a series of experiments on chalk saturated with glycol and sodium chloride solutions of various concentrations. These experimental data are used to validate the applicability of the proposed intergranular stress. Fig. 5(a) shows the results of the 'Brazilian' tests on the chalk saturated with different fluids. It is clear that the glycol-saturated chalk is considerably stronger than the water-saturated chalk. In particular, the tensile strength showed a clear dependency on the concentration and ionic strength of salt. When the salt content increases, the tensile strength of the chalk increases. Such an effect becomes more pronounced if a higher ionic strength solution is used.

As in the oil-saturated rock, the rock-fluid interaction in the glycol-saturated samples is generally weak, so that the glycol-saturated chalk can be assumed as the reference state, at which $\Pi=0$. In contrast to the oil, however, glycol is completely miscible with water so that any capillary effect is ruled out. The generalised osmotic pressure, $\Pi$, can be used to determine the shear strength difference between two chalk samples saturated with different solutions. To determine $\Pi$, one has to evaluate the Donnan osmotic pressure (i.e. $\Pi_{\mathrm{D}}$ ) and the pressure associated with the surface force potential (i.e. $\rho_{\oplus}^{l_{\mathrm{H}_{2} \mathrm{O}}} \Omega_{0}^{l}$ ), as evident by equation (5).

To proceed it is necessary first to note that a brine with $700 \mathrm{~g} / 1$ calcium chloride is close to the solubility limit of calcium chloride. This implies that, in this particular

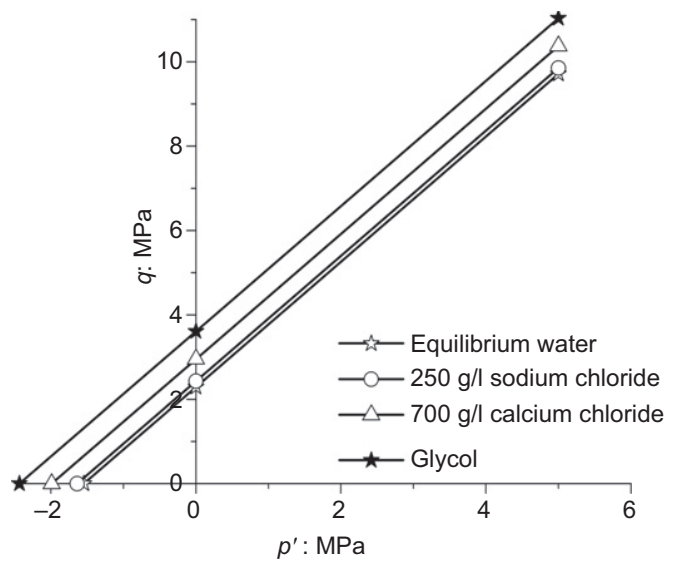

(a)

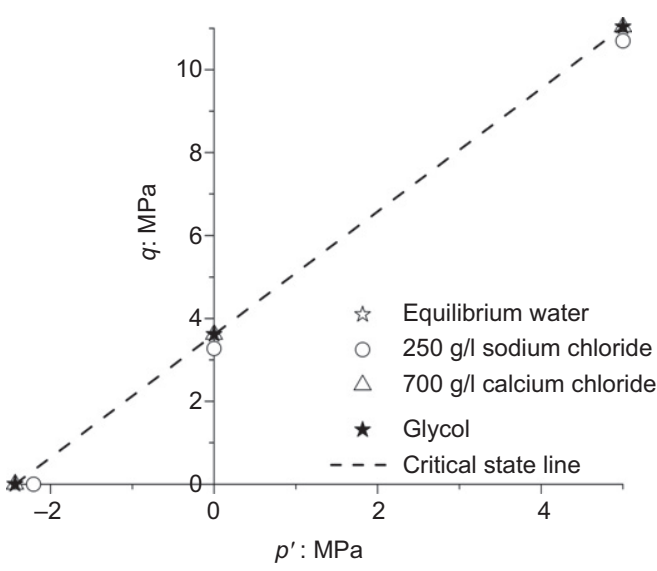

(b)

Fig. 5. Failure lines of chalks saturated with different fluids: (a) in the $p^{\prime}-q$ plane; (b) in the $p^{\prime \prime}-q$ plane 
case, $\Pi_{\mathrm{D}}$ should be very small, compared with $\left(-\rho_{\oplus}^{l_{\mathrm{H}_{2} \mathrm{O}}} \Omega_{0}^{l}\right)$, so that $\Pi \approx-\rho_{\oplus}^{l_{\mathrm{H}_{2} \mathrm{O}}} \Omega_{0}^{l}$. Hence, the pressure associated with the surface force of the chalk saturated with $700 \mathrm{~g} / 1$ calcium chloride can be calculated as (see Fig. 4): $-\rho_{\oplus}^{l_{\mathrm{H}_{2} \mathrm{O}}} \Omega_{0}^{l}=$ $\Delta c / M=0.445 \mathrm{MPa}$, where $M$ assumes a value of 1.2 based on the experimental data (Risnes et al., 2003). In general, the initial surface force potential $\Omega_{0}^{l}$ at full saturation could be influenced by both the type and concentration of ions in the saturating fluids. Unfortunately, the experimental data in this regard are simply lacking. Here, it is assumed for convenience that the effects of the type and concentration of the saturating fluids on $\Omega_{0}^{l}$ are negligible. As such, in the calculations, the pressure associated with the surface force potentials (i.e. $\rho_{\oplus}^{l_{\mathrm{H}_{2} \mathrm{O}}} \Omega_{0}^{l}$ ) assumes the same value of $-0.445 \mathrm{MPa}$.

To evaluate the Donnan osmotic pressure $\Pi_{\mathrm{D}}$, it is necessary to determine the fixed charge density of the chalk. The CEC of chalk is approximately equal to $0 \cdot 4$ (eq/l rock) (Andersen et al., 2012), from which the fixed negative charges density is inferred as $c_{\text {fix }}=400 \mathrm{~mol} / \mathrm{m}^{3}$. Now the Donnan osmotic pressure, $\Pi_{D}$, for the chalks saturated with different salt concentrations (except for $700 \mathrm{~g} / 1$ calcium chloride) can be calculated using equation (3) (see the Appendix). Noticeably, the chalk matrix may contain a small number of dissoluble ions. Thus, the equilibrium solution of the water-saturated chalk may have some initial concentration. Because no experimental data are available about such an initial concentration, it is assumed ad hoc as $1.25 \mathrm{~mol} / \mathrm{l}$ in the calculations.

Once both $\Pi_{\mathrm{D}}$ and $\left(-\rho_{\oplus}^{l_{\mathrm{H}_{2} \mathrm{O}}} \Omega_{0}^{l}\right)$ have been determined, the generalised osmotic pressure, $\Pi$, can be calculated using equation (5). The $\Pi$ values obtained for all the chalk samples saturated with different fluids are summarised in Table 1. Fig. 5 illustrates the failure lines for the chalk samples saturated with different solutions, which are presented in both the $p^{\prime}-q$ plane and the $p^{\prime \prime}-q$ plane for comparison. Clearly, the failure lines are very divergent when presented with respect to Terzaghi's effective stress (Fig. 5(a)), but they converge into the vicinity of a single line when presented using the proposed intergranular stress (Fig. 5(b)).

Risnes et al. (2005) studied the mechanical properties of high porosity outcrop chalk $(>40 \%)$ with mixtures of water and glycol. Fig. 6 shows the variation of cohesion with water content obtained from 'Brazilian' tests, where the empty asterisk represents the cohesion obtained by Terzaghi's effective stress. The experimental results indicate that the cohesion increases with the decrease of the water content. Because water and glycol are fully miscible, the capillary effect is ruled out, and the weakening effect is solely due to the physicochemical interactions between the pore fluid and the chalk matrix. In this case, $\Omega_{0}^{l}$ of the sample saturated with mixtures of water and glycol is contributed only by water, which can be calculated by $\Omega_{0}^{l}$ when the sample is fully water saturated, multiplied by water saturation, that is, $\Omega_{0}^{l}($ water and glycol saturated $)=\Omega_{0}^{l}($ water saturated $) \times S_{\mathrm{r}}$, and $\Pi_{\mathrm{D}}$ at different water contents can be calculated using equation (3). When the generalised osmotic pressure is obtained (by using equation (5)), the apparent cohesion is

Table 1. Generalised osmotic pressure in chalks saturated with different fluids

\begin{tabular}{l|l|c|c|c}
\hline $\begin{array}{l}\text { Saturating } \\
\text { fluid }\end{array}$ & Glycol & $\begin{array}{c}700 \mathrm{~g} / 1 \\
\text { calcium } \\
\text { chloride }\end{array}$ & $\begin{array}{c}250 \mathrm{~g} / 1 \\
\text { sodium } \\
\text { chloride }\end{array}$ & $\begin{array}{c}\text { Equilibrium } \\
\text { water }\end{array}$ \\
\hline$\Pi: \mathrm{MPa}$ & 0 & 0.445 & 0.568 & 0.89 \\
\hline
\end{tabular}

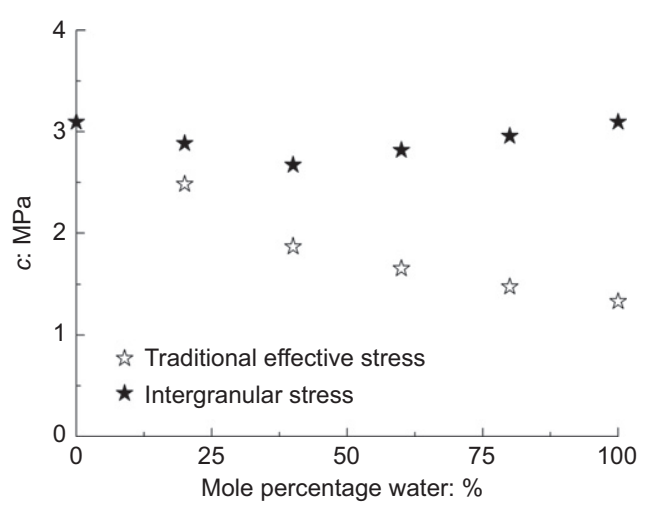

Fig. 6. Cohesion plotted against fluid composition (data from Risnes et al., 2005)

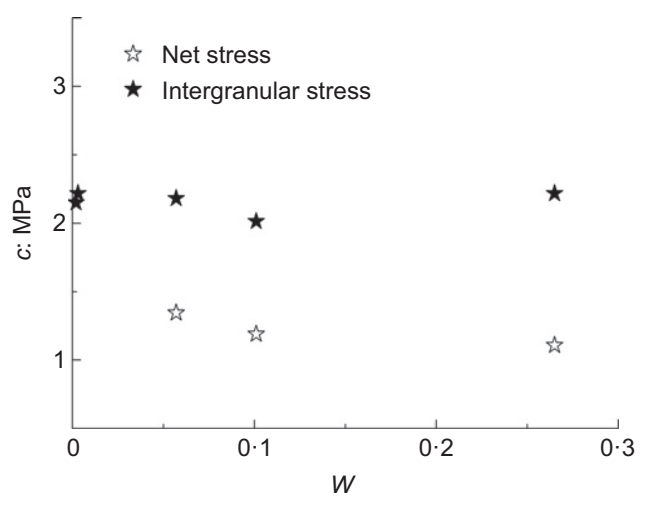

Fig. 7. Variation of cohesion with water content for Lewes chalk (data after Taibi et al., 2009)

obtained by $c=c_{\mathrm{r}}-M \Pi$, where $M$ is equal to $1 \cdot 2$, corresponding to the typical value for a friction angle of $30^{\circ}$. The results are given in Fig. 6. Clearly, in terms of the proposed intergranular stress, the cohesion remains practically unchanged as the volume fraction of water increases, although a slight discrepancy can be seen at the intermediate water content. The discrepancy is probably due to the uncertainty about the dependence of the surface force potential on the saturating fluid. Hence, in terms of the proposed intergranular stress, the cohesion is an intrinsic parameter, and the failure line can be considered to be unique.

Taibi et al. (2009) studied the effect of suction on the hydro-mechanical behaviour of two kinds of chalks under low confining pressures. These authors found that the apparent cohesion varied by a factor of 2 to 3 when the state of chalk changed from dry to fully water-saturated. At the natural water content, the behaviour of chalk is intermediate between the dry and fully saturated states. Figs 7 and 8 show the variations of cohesion with water content for Lewes and Seaford chalks, obtained from the uniaxial compression tests, in which the empty asterisks represent the cohesion obtained by the mean net stress (the total stress minus pore air pressure). Similarly to the saturated chalks, the cohesions of the two unsaturated chalks increase with the decrease of the water content. By virtue of the measured water retention curves, the intergranular stress can be calculated by equation (6). It can be seen from Figs 7 and 8 that when the experimental data are presented in terms of the proposed intergranular stress, the apparent cohesion remains almost unchanged as the water content varies. 


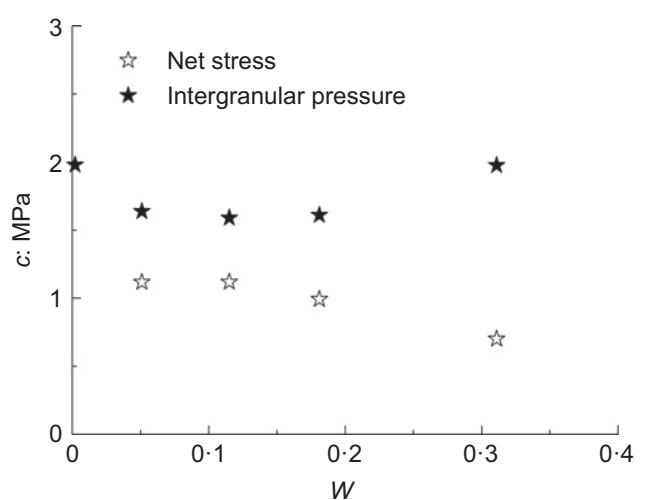

Fig. 8. Variation of cohesion with water content for Seaford chalk (data after Taibi et al., 2009)

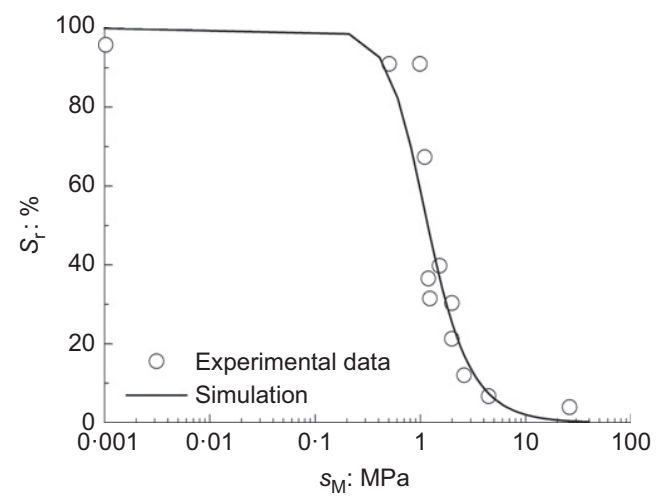

(a)

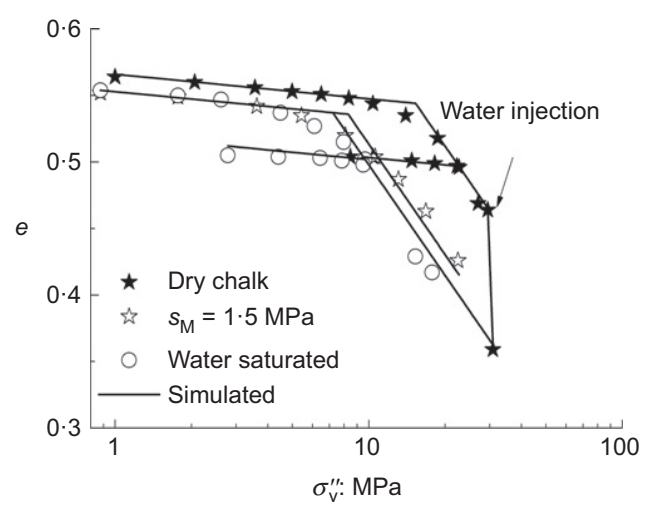

(b)

Fig. 9. (a) Water retention characteristic curves of Estreux chalk. (b) The compression curves under different compression tests: relationship between void ratio $e$ and vertical intergranular stress, $\sigma_{\mathrm{v}}^{\prime \prime}$
Suction-controlled oedometer tests

De Gennaro et al. (2005) studied the effect of suction on the mechanical response of Estreux chalk by performing a series of oedometer tests. The water retention curve of the Estreux chalk was obtained by the osmotic technique with vapour phase control (Fig. 9(a)). The experimental data of the water retention characteristics were fitted using van Genutchen's model, and the capillary hysteresis effect was neglected. Fig. 9(b) shows the results of three compression tests performed on the Estreux chalk samples with various degrees of water saturation, that is, fully saturated, dry and partially saturated, under a controlled matric suction of $1.5 \mathrm{MPa}$. The material parameters in the simulations are summarised in Table 2. As expected for all the partially saturated geomaterials, the yielding pressure of the chalk with a varying degree of saturation is suctiondependent; that is, with a decrease in matric suction or an increase in water content, the chalk becomes weaker and weaker. As shown in Fig. 9(b), when the water was injected into the dry chalk under a vertical loading of $29 \cdot 3 \mathrm{MPa}$, collapsible deformation occurred in the chalk, and after 12 days of continuous infiltration, the final state of the chalk attained the compression curve of the saturated chalk. Comparison between the theoretical simulations and the experimental results shows that the proposed model can capture well the main features of the mechanical behaviour of the chalk.

Homand \& Shao (2000a) carried out a series of conventional hydrostatic and triaxial compression tests on Ekofisk chalk samples. The chalk samples were saturated with water and oil, respectively. The experimental results and theoretical simulations are given in Figs 10-13 for some representative experiments, where the sensitivity of chalk behaviour to the saturating fluid is clearly shown. The material parameters in the simulations are summarised in Table 3.

Figure 10 shows the stress-strain relationships obtained in the hydrostatic compression tests performed on 'oilsaturated' and 'water-saturated' samples, respectively. It can be seen that the plastic yield stress is drastically reduced when the chalk is saturated with water. In addition, it is shown that the magnitude of the compression index is practically the same for both the water-saturated and soltrol-saturated Ekofisk chalks. The good agreement between theoretical simulation and experimental data indicates that the waterweakening effect of chalk has been very well described by the proposed model.

Figure 11 shows the yield surfaces and the failure surfaces derived from the triaxial tests on the Ekofisk chalk samples saturated with two different fluids. It is noted that the initial elastic domain is significantly reduced in the water-saturated chalk. The water saturation seems to affect essentially the plastic pore collapse mechanism. The slope of the failure

Table 2. Material parameters of Estreux chalk

\begin{tabular}{c|c|c|c|c|c|c|c|c}
\hline$\lambda$ & $\kappa$ & $p_{\mathrm{c} 0}^{*}: \mathrm{MPa}$ & $\beta$ & $\Pi_{0}: \mathrm{MPa}$ & $N$ & $\alpha$ & $c_{\mathrm{r}}: \mathrm{MPa}$ & $M$ \\
\hline 0.12 & 0.008 & $15 \cdot 3$ & 0.77 & 0.8 & 2.61 & 0.89 & 2.0 & 1.0 \\
\hline
\end{tabular}

Table 3. Material parameters of Ekofisk chalk

\begin{tabular}{c|c|l|c|c|c|c|c|c}
\hline$\lambda$ & $\kappa$ & $E: \mathrm{MPa}$ & $v$ & $p_{\mathrm{c} 0}^{*}: \mathrm{MPa}$ & $\beta$ & $\Pi_{0}: \mathrm{MPa}$ & $c_{\mathrm{r}}: \mathrm{MPa}$ & $M$ \\
\hline $0 \cdot 16$ & $0 \cdot 003$ & 4200 & $0 \cdot 2$ & $17 \cdot 4$ & $0 \cdot 94$ & $0 \cdot 8$ & $2 \cdot 0$ & $1 \cdot 0$ \\
\hline
\end{tabular}




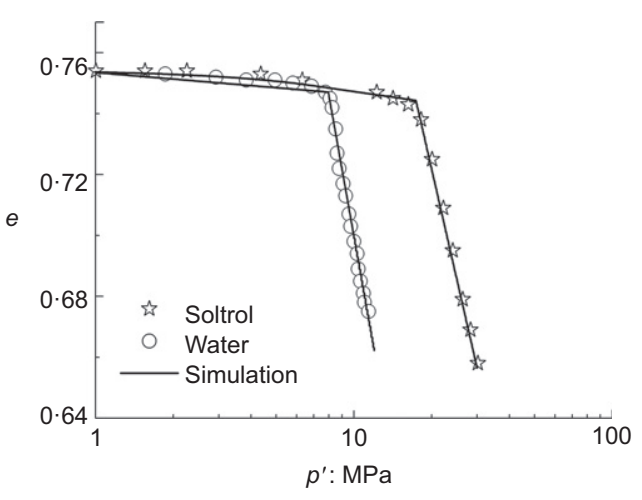

Fig. 10. Theoretical simulation and experimental results of hydrostatic compression tests

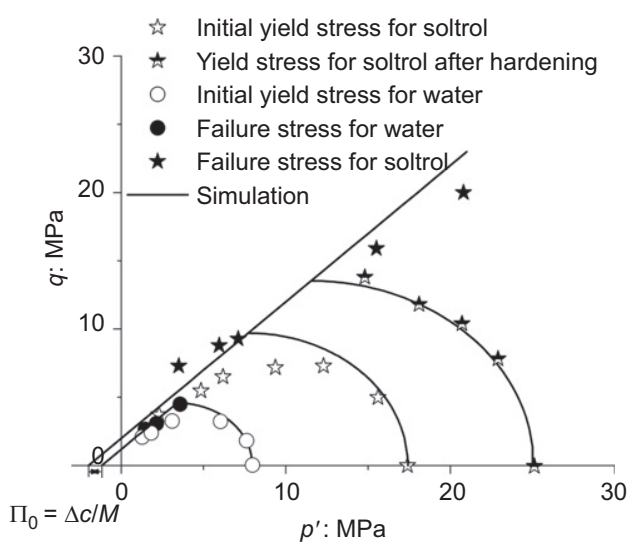

Fig. 11. Yield and failure surfaces of soltrol- and water-saturated chalk samples

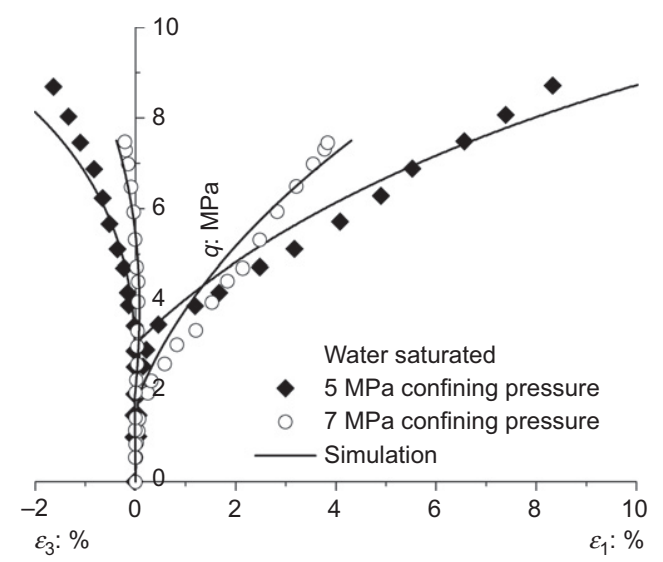

Fig. 12. Simulations of triaxial tests for different confining pressures (water saturated)

lines is approximately the same for the two samples, which can be assumed as $M=1 \cdot 0$. With the soltrol-saturated chalk being the reference state, the generalised osmotic pressure of water-saturated chalk can be obtained from the difference of apparent cohesion between the two samples, that is, $\Pi_{0}=\Delta c / M$, as shown in Fig. 11 .

Figures 12 and 13 compare the simulated and experimental results of the triaxial compression tests on the water- and oil-saturated Ekofisk chalk samples under different confining pressures. Theoretical simulations are performed by using the proposed chemo-mechanical coupling constitutive model.

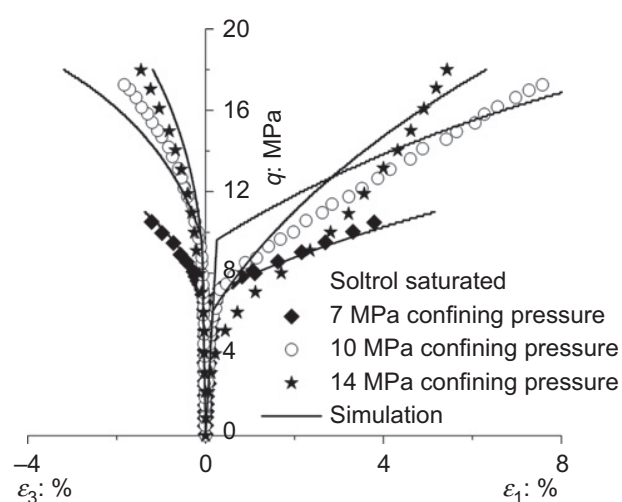

Fig. 13. Simulation of triaxial tests for different confining pressures (soltrol saturated)

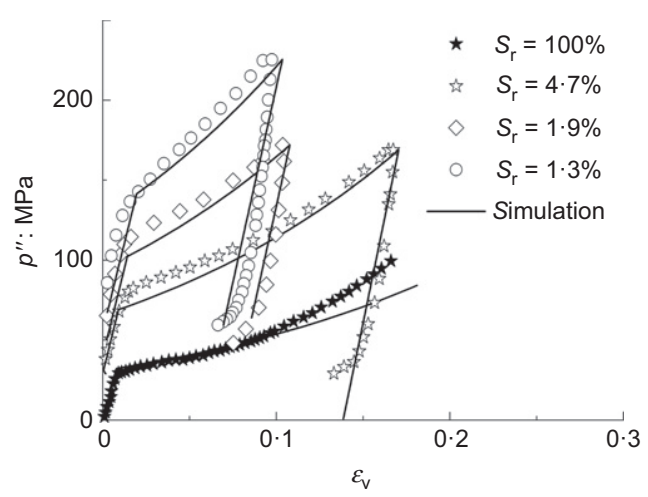

Fig. 14. Pietra Leccese batch I: theoretical simulations and experimental results of hydrostatic compression tests on specimens with various saturations: relationship between the volumetric strain $\varepsilon_{\mathrm{v}}$ and mean intergranular stress $p^{\prime \prime}$

Comparison with the experimental results shows that the model can describe the main characteristic. The watersaturated chalk under a 'low' confining pressure (say $<3 \mathrm{MPa}$ ) shows brittle behaviour, which cannot be captured using the simple Cam Clay model. Hence, the comparisons are performed only for those samples subjected to 'high' confining pressures $(\geq 5 \mathrm{MPa})$. It is remarkable that the proposed model is capable of capturing the main features of the mechanical behaviour of chalk at the two extreme states, that is, 'oil saturated' and 'water saturated', using a single set of material parameters.

Papamichos et al. (1997) conducted a series of experiments on Pietra Leccese chalk with different degrees of water saturation, and the results revealed that some material parameters depend strongly on the water saturation and the capillary suction. In these experiments, the chalk specimens were sampled from two blocks of Pietra Leccese, named batch I and batch II, which were quite different in terms of their mechanical and petrophysical properties. Figs 14-16 show the results of these experiments and model simulations. The material parameters are calibrated based on the experimental results and shown in Table 4.

Figure 14 compares the model simulations and the experimental results for the hydrostatic compression tests on the chalk specimens batch I with the degree of saturation of $1.3,1.9,4 \cdot 7$ and $100 \%$. It can be clearly seen that only a small amount of water injected into the pores could significantly weaken the chalk material. This feature can be captured well by the proposed model. To explore the underlying mechanisms of the water-weakening effect, the 


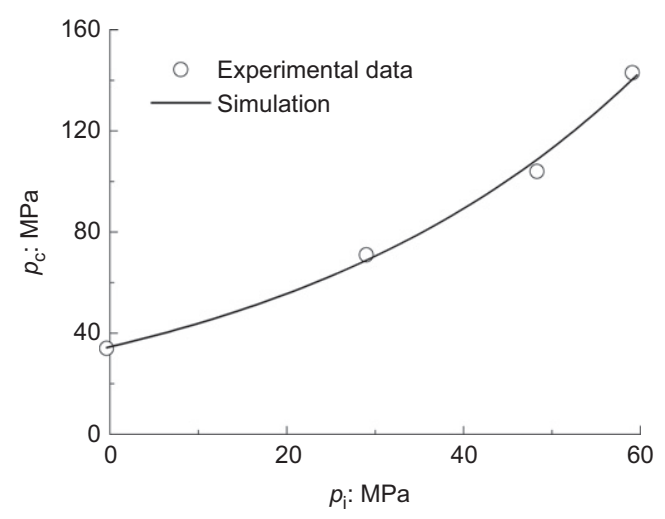

Fig. 15. Pietra Leccese batch I: relationship between internal pressure and yield pressure

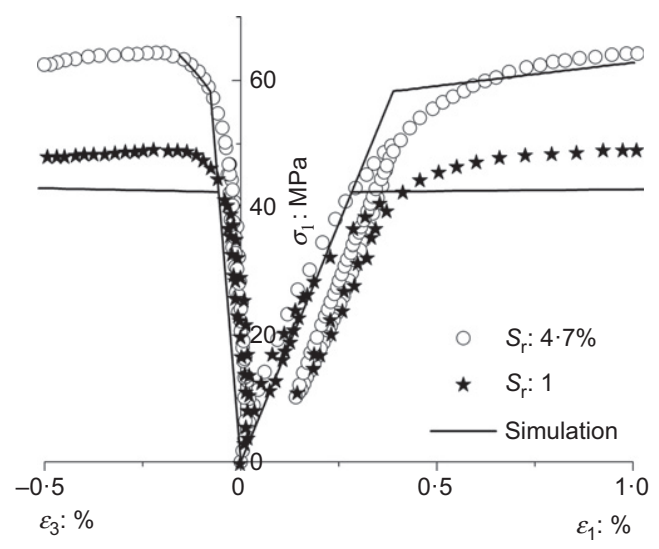

Fig. 16. Pietra Leccese batch II: theoretical simulations and experimental results of triaxial compression tests at confining stress $10 \mathrm{MPa}$ on specimens with various saturations

intrinsic intergranular pressure $p_{\mathrm{i}}$ is calculated for different degrees of saturation, and the relationship between the intrinsic intergranular pressure and the yielding pressure $\left(p_{\mathrm{c}}\right)$ is shown in Fig. 15. Clearly, as $p_{\mathrm{i}}$ increases, $p_{\mathrm{c}}$ increases, that is, the chalk becomes stronger. Fig. 16 compares the model simulations and the experimental results of the triaxial compression tests on specimens from batch II with a degree of saturation of 4.7 and $100 \%$, where $\sigma_{1}$ means the axial net stress, the total stress minus the pore air pressure. Noticeably, both the experimental and theoretical results clearly demonstrate that the physicochemical interaction between water and chalk matrix can exert a significant influence on the mechanical behaviour of reservoir rocks. Such a mechanism has been largely underestimated in the petroleum industry.

Figure 17 demonstrates the effect of water injection on the $K_{0}$ compression of a chalk under constant axial stresses, where $\sigma_{1}$ means the axial net stress, the total stress minus the pore air pressure. During the experiment, the chalk specimen saturated with oil is compressed under the $K_{0}$ condition until a prescribed level of axial stress is reached; then, water is injected into the sample under constant axial stress; when the

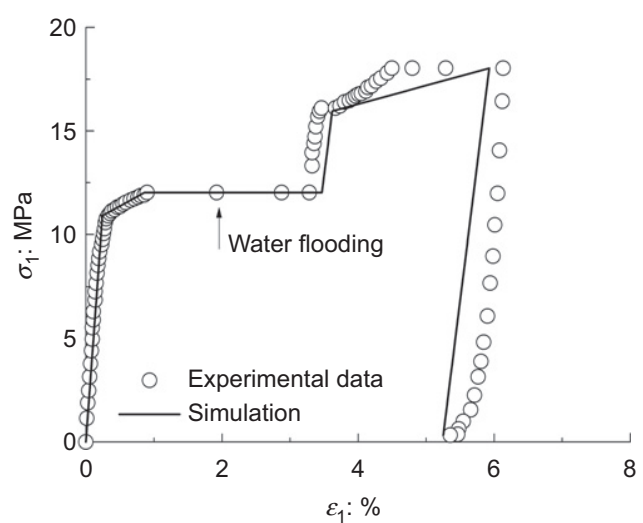

Fig. 17. Effect of water injection on the $K_{0}$ compression of Stevns Klint chalk (data after Hickman (2004))

water injection ceases and the specimen is again compressed under the $K_{0}$ condition to a prescribed axial stress level, from which the specimen is finally unloaded to zero stress. Experimental results clearly show that the water injection can induce significant deformation of chalk even under constant axial stress. As clearly shown in Fig. 17, the mechanical response of the chalk can be very well described by the proposed constitutive model.

\section{CONCLUSIONS}

A conceptual elastoplastic model is developed for describing the chemo-mechanical behaviour of chalk, based on the framework of the modified Cam Clay model and the concept of intergranular stresses. To address the effect of the physicochemical interactions between the pore fluid and the solid matrix, a macroscopic surface force potential is explicitly defined. It turns out that the surface potential can be expressed as an integral function of matric suction and the Donnan osmotic pressure. By enforcing the equilibrium condition, the composition and significance of pore water pressure is analysed, and in particular the Donnan osmotic pressure is defined. An explicit equation is given for the intergranular stress, which can be used as the substitute for Terzaghi's effective stress to describe the chemo-mechanical behaviour of chalk. To address the hardening effect of the microscopic physicochemical interactions, the preconsolidation pressure function in the modified Cam Clay model is changed by introducing the intrinsic intergranular pressure as an additional hardening variable that accounts solely for the chalk-fluid interaction.

It is shown that the proposed concept of intergranular stresses can address well the effects of osmosis, adsorption and capillarity on the chalk behaviour in a consistent and systematic way. Experimental results for chalk materials saturated with different fluids are simulated to illustrate the performance of the proposed model. Comparisons between the theoretical simulations and experimental results clearly demonstrate that the proposed model is capable of capturing the main features of the chemo-mechanical behaviour of

Table 4. Material parameters for Pietra Leccese chalk

\begin{tabular}{l|c|c|l|c|c|c|c|c|c|c|c}
\hline Rock type & $\lambda$ & $\kappa$ & $E: \mathrm{MPa}$ & $v$ & $p_{\mathrm{c} 0}^{*}: \mathrm{MPa}$ & $\beta$ & $\Pi_{0}: \mathrm{MPa}$ & $c_{\mathrm{r}}: \mathrm{MPa}$ & $M$ & $n$ & $\alpha$ \\
\hline Batch I & 0.273 & 0.028 & 7800 & 0.2 & $34 \cdot 6$ & 0.0237 & 0.38 & - & - & 0.17 & $1 \cdot 69$ \\
Batch II & 0.173 & 0.028 & 15000 & $0 \cdot 2$ & $49 \cdot 3$ & 0.0149 & 0.38 & $2 \cdot 5$ & $1 \cdot 8$ & 0.416 & 1.912 \\
\hline
\end{tabular}


chalk saturated with an individual or two (miscible or immiscible) fluids. Although the proposed model is developed for chalk materials, it is generally suited to simulate the mechanical behaviour of partially saturated porous media, in which physicochemical effects come into play.

\section{ACKNOWLEDGEMENT}

The research was supported by the Natural Science Foundation of China (NSFC) under grants 11502276, 41572293 and 51639008.

\section{APPENDIX. CALCULATION OF DONNAN OSMOTIC PRESSURE}

Consider a thermodynamic system composed of a solution-filled reservoir and a body of water-saturated chalk (see Fig. 2), where the water solution in the reservoir remains in contact, and in equilibrium, with the pore water in the chalk. Suppose that the chalk has a fixed negative charge density of $c_{\text {fix }}\left[\right.$ moles $\left./ \mathrm{m}^{3}\right]$, which represents the total number of electric charges fixed in a unit volume of the chalk. It is assumed that both the equilibrium solution in the reservoir and the pore water are composed of a solvent (water $\left(\mathrm{H}_{2} \mathrm{O}\right)$ ) and two charged species, $X^{m-}$ and $Y^{n+}$, whose valence number is $-m$ and $n$, respectively.

Consider point $\mathrm{A}$ in the equilibrium solution in the reservoir, which is at the same elevation as point B in the chalk. The condition of electrical neutrality requires that

$$
\begin{aligned}
& n c_{\mathrm{A}}^{l_{Y n+}}=m c_{\mathrm{A}}^{l_{X m-}}=c_{0} \\
& n c^{l_{Y n+}}=m c^{l_{X m-}}+\frac{c_{\mathrm{fix}}}{n^{l}}
\end{aligned}
$$

where $c_{0}\left[\mathrm{moles} / \mathrm{m}^{3}\right]$ is the molar concentration of equilibrium solution; $c^{l_{Y_{n+}+}}$ and $c^{l_{X_{m-}}}$ are the molar concentrations of $Y^{n+}$ and $X^{m-}$, respectively, in the pore water; and subscript ' $\mathrm{A}$ ' indicates point A in the reservoir.

The equilibrium condition requires that (Wei, 2014)

$$
\mu_{\mathrm{A}}^{l_{i}}=\mu_{\mathrm{B}}^{l_{i}}, \quad i=\mathrm{H}_{2} \mathrm{O}, X^{m-}, Y^{n+}
$$

where $\mu_{\mathrm{A}}^{l_{i}}$ and $\mu_{\mathrm{B}}^{l_{i}}$ are the chemical potential of species $i$ at point $\mathrm{A}$ and point $\mathrm{B}$, respectively

$$
\begin{aligned}
& \mu_{\mathrm{A}}^{l_{\mathrm{H}_{2} \mathrm{O}}}=\mu_{\oplus}^{l_{\mathrm{H}_{2} \mathrm{O}}}\left(T, p_{0}^{l}\right)+\frac{\left(p_{\mathrm{A}}^{l}-p_{0}^{l}\right)}{\rho_{\oplus}^{l_{\mathrm{H}_{2} \mathrm{O}}}}+\frac{R T}{m_{\mathrm{H}_{2} \mathrm{O}}} \ln a_{\mathrm{A}}^{l_{\mathrm{H}_{2} \mathrm{O}}} \\
& \mu_{\mathrm{B}}^{l_{\mathrm{H}_{2} \mathrm{O}}}=\mu_{\oplus}^{l_{\mathrm{H}_{2} \mathrm{O}}}\left(T, p_{0}^{l}\right)+\frac{\left(p^{l}-p_{0}^{l}\right)}{\rho_{\oplus}^{l_{\mathrm{H}_{2}} \mathrm{O}}}+\frac{R T}{m_{\mathrm{H}_{2} \mathrm{O}}} \ln a^{l_{\mathrm{H}_{2} \mathrm{O}}}+\Omega^{l} \\
& \mu_{\mathrm{A}}^{l_{y}}=\mu_{\oplus}^{l_{y}}\left(T, p_{0}^{l}\right)+\frac{p_{\mathrm{A}}^{l}-p_{0}^{l}}{\rho_{\oplus}^{l_{y}}}+\frac{R T}{m_{\gamma}} \ln a_{\mathrm{A}}^{l_{y}} \\
& \mu_{\mathrm{B}}^{l_{y}}=\mu_{\oplus}^{l_{y}}\left(T, p_{0}^{l}\right)+\frac{p^{l}-p_{0}^{l}}{\rho_{\oplus}^{l_{y}}}+\frac{R T}{m_{\gamma}} \ln a^{l_{y}}+\Omega^{l}+\frac{F \xi v_{\gamma}}{m_{\gamma}}
\end{aligned}
$$

where $\gamma=X^{m-}, Y^{n+} ; p_{0}^{l}$ is the pressure of pure water at some reference state; $\mu_{\oplus}^{l_{\mathrm{H} 2} \mathrm{O}}$ is the chemical potential of pure water; and $\rho_{\oplus}^{l_{\oplus}}$ and $\mu_{\oplus}^{l_{\oplus}}$ are the mass density and chemical potential, respectively, of species $\gamma$ at the pure state.

By substituting equations (21) and (22) into equation (18), one can prove that (Wei, 2014), for a dilute solution

$$
\left(m^{l_{X^{m-}}}\right)^{n}\left(m^{l_{Y^{n+}}}\right)^{m}=\left(m_{\mathrm{A}}^{l_{X m-}}\right)^{n}\left(m_{\mathrm{A}}^{l_{Y n+}}\right)^{m}
$$

where $m^{l_{Y n+}}$ and $m^{l_{X_{m-}}}$ are the molar fractions of $Y^{n+}$ and $X^{m-}$, respectively. Now equations (16), (17) and (23) can be solved simultaneously for $c^{l_{X m-}}$ and $c^{l_{Y n+}}$. Provided that $c_{0}, c_{\mathrm{fix}}$ and $n^{l}$ are specified, the Donnan osmotic pressure can be obtained by

$$
\Pi_{\mathrm{D}}=\frac{R T \rho_{\oplus}^{l_{\mathrm{H}_{2} \mathrm{O}}}}{m_{\mathrm{H}_{2} \mathrm{O}}} \ln \left(\frac{m_{\mathrm{A}}^{l_{\mathrm{H}_{2} \mathrm{O}}}}{m^{l_{\mathrm{H}_{2} \mathrm{O}}}}\right)
$$

where $m_{\mathrm{A}}^{l_{\mathrm{H}_{2} \mathrm{O}}}$ and $m^{l_{\mathrm{H}_{2} \mathrm{O}}}$ are the molar fraction of the solvent in the reservoir and in the pores, respectively.

\section{NOTATION}

$a^{l_{i}}$ activity of specifies $l_{i}$

$C^{l_{i}}$ mass fraction of species $l_{i}$

$c$ apparent cohesion

$c_{0}$ molar concentration of equilibrium solution

$c_{\text {fix }}$ fixed charge density

$c^{l_{i}}$ molar concentration of species $l_{i}$

$c_{\mathrm{r}}$ apparent cohesion of the chalk at the reference state

$\mathrm{d} \varepsilon_{i j}, \mathrm{~d} \varepsilon_{i j}^{\mathrm{e}}, \mathrm{d} \varepsilon_{i j}^{\mathrm{p}}$ total, elastic and plastic strain increments

$\mathrm{d} \lambda$ plastic multiplier

$E$ Young's modulus

$e$ void ratio

$F \quad$ Faraday's constant

$f$ yield function

$M$ slope of the critical state line

$M_{\mathrm{H}_{2} \mathrm{O}}$ molar mass of water

$m^{l_{i}} \quad$ molar fraction of species $l_{i}$ in the solution

$n^{1}$ volume fraction of the liquid phase

$p_{\mathrm{c}} \quad$ preconsolidation pressure

$p_{\mathrm{c} 0}$ preconsolidation pressure when the chalk is fully saturated with water

$p_{\mathrm{c} 0}^{*} \quad$ initial preconsolidation pressure of chalk

$p^{g}$ pore air pressure or oil pressure

$p_{\mathrm{i}}$ intrinsic intergranular pressure

$p_{l}^{l} \quad$ true water pressure

$p_{0}^{l} \quad$ pressure of pure water at some reference state

$p_{\mathrm{W}}^{l} \quad$ measured water pressure of the equilibrium solution

$p^{\prime}$ mean Terzaghi's effective pressure

$p^{\prime \prime}$ mean intergranular pressure

$q$ deviatoric intergranular stress

$R$ universal gas constant

$S_{\mathrm{r}}$ degree of water saturation

$s_{i j} \quad$ components of deviatoric stress

$s_{\mathrm{M}}$ matric suction

$T$ Kelvin temperature

$w$ water content

$\alpha, n \quad$ van Genuchten model parameters

$\beta$ hardening parameter

$\varepsilon_{\mathrm{v}}^{\mathrm{p}}$ plastic volumetric strain

$\varepsilon_{1}$ axial strain

$\lambda, \kappa$ slopes of the normal consolidation line and the unloading-reloading line on the $v-\ln p_{(\mathrm{I})}^{\prime}$ plane, respectively

$\mu^{l_{i}} \quad$ chemical potential of species $l_{i}$

$\mu_{\oplus}^{l_{i}} \quad$ chemical potential of species $l_{i}$ at the pure state

$v$ Poisson's ratio

$\xi$ local electrostatic potential

$\Pi$ generalised osmotic pressure

$\Pi_{\mathrm{D}}$ Donnan osmotic pressure

$\Pi_{0} \quad$ initial generalised osmotic pressure of the water-saturated sample

$\rho_{\mathrm{d}} \quad$ dry density of the sample

$\rho^{l} \quad$ mass density of the pore solution

$\rho_{\oplus}^{l_{i}} \quad$ mass density of species $l_{i}$ in pure state

$\boldsymbol{\sigma}$ total stress tensor

$\sigma^{\prime}$ Terzaghi's effective stress tensor

$\sigma^{\prime \prime} \quad$ intergranular stress tensor

$\sigma_{1}$ axial net stress

$v$ specific volume

$\phi$ porosity of the chalk

$\Omega^{l} \quad$ surface force potential

$\Omega_{0}^{l} \quad$ surface force potential at full saturation

1 second-order unit tensor, with components of $\delta_{i j}$ 


\section{REFERENCES}

Alonso, E. E., Gens, A. \& Josa, A. (1990). A constitutive model for partially saturated soils. Géotechnique 40, No. 3, 405-430, https://doi.org/10.1680/geot.1990.40.3.405.

Andersen, P. Ø., Evje, S., Madland, M. V. \& Hiorth, A. (2012). A geochemical model for interpretation of chalk core flooding experiments. Chem. Engng Sci. 84, 218-241.

Collin, F., Cui, Y. J., Schroeder, C. \& Charlier, R. (2002). Mechanical behaviour of Lixhe chalk partly saturated by oil and water: experiment and modelling. Int. J. Numer. Analyt. Methods Geomech. 26, No. 9, 897-924.

De Gennaro, V., Delage, P., Cui, Y. J., Schroeder, C. \& Collin, F. (2003). Time-dependent behaviour of oil reservoir chalk: a multiphase approach. Soils Found. 43, No. 4, 131-148.

De Gennaro, V., Delage, P., Priol, G., Collin, F. \& Cui, Y. J. (2004). On the collapse behaviour of oil reservoir chalk. Géotechnique 54, No. 6, 415-420, https://doi.org/10.1680/geot. 2004.54.6.415.

De Gennaro, V., Sorgi, C. \& Delage, P. (2005). Air-water interaction and time dependent compressibility of a subterranean quarry chalk. Proceedings of symposium post mining 2005, Nancy, France.

Delage, P., Schroeder, C. \& Cui, Y. J. (1996). Subsidence and capillary effects in chalks. In Proceedings of Eurock '96 (ed. G. Barla), pp. 1291-1298. Rotterdam, the Netherlands: Balkema.

Duperret, A., Taibi, S., Mortimore, R. N. \& Daigneault, M. (2005). Effect of groundwater and sea weathering cycles on the strength of chalk rock from unstable coastal cliffs of NW France. Engng Geol. 78, No. 3-4, 321-343.

EC (European Commission) (2004). Mechanical behaviour of partially and multiphase saturated chalks. Fluid-skeleton interaction: main factor of chalk oil reservoirs compaction and related subsidence - part 2 (PASACHALK 2), contract no. ENK6-2000-00089. Brussels, Belgium: European Commission.

Gonçalvès, J., Rousseau-Gueutin, P., De Marsily, G., Cosenza, P. \& Violette, S. (2010). What is the significance of pore pressure in a saturated shale layer? Water Resour. Res. 46, No. 4, W04514, https://doi.org/10.1029/2009WR008090.

Halleux, L., Detiege, C., Poot, B., Schroeder, C., Monjoie, A., Debande, G. \& Da Silva, F. (1990). Mechanical behavior of chalks. Proceedings of the 3rd North Sea chalk symposium, Copenhagen, Denmark.

Heggheim, T., Madland, M., Risnes, R. \& Austad, T. (2005). A chemical induced enhanced weakening of chalk by seawater. J. Petrol. Sci. Engng 46, No. 3, 171-184.

Hellmann, R., Renders, P. J., Gratier, J. P. \& Guiguet, R. (2002). Experimental pressure solution compaction of chalk in aqueous solutions. Part 1. Deformation behavior and chemistry. In Water-rock interactions, ore deposits, and environmental geochemistry: a tribute to David A. Crerar (eds R. Hellmann and S. A. Wood), Special Publication No. 7, pp. 129-152. Washington, DC, USA: The Geochemical Society.

Hickman, R. J. (2004). Formulation and implementation of a constitutive model for soft rock. $\mathrm{PhD}$ thesis, Virginia Polytechnic Institute and State University, Blacksburg, VA, USA.

Hiorth, A., Cathles, L. \& Madland, M. (2010). The impact of pore water chemistry on carbonate surface charge and oil wettability. Transp. Porous Med. 85, No. 1, 1-21.

Homand, S. \& Shao, J. F. (2000a). Mechanical behaviour of a porous chalk and water/chalk interaction, part I: experimental study. Oil Gas Sci. Technol. 55, No. 6, 591-598.

Homand, S. \& Shao, J. F. (2000b). Mechanical behaviour of a porous chalk and water/chalk interaction, part II: numerical modelling. Oil Gas Sci. Technol. 55, No. 6, 599-609.

Keszthelyi, D., Dysthe, D. K. \& Jamtveit, B. (2016). Compaction of North-sea chalk by pore-failure and pressure solution in a producing reservoir. Frontiers in Physics 4, No. 4, 1-10.

Lawrence, J. A., Mortimore, R. N., Stone, K. J. \& Busby, J. P. (2013). Sea saltwater weakening of chalk and the impact on cliff instability. Geomorphology 191, 14-22.
Lord, C. J., Rhett, D. W. \& Johlman, C. L. (1998). Is capillary suction a viable cohesive mechanism in chalk? In Rock mechanics in petroleum engineering: Eurock '98 proceedings, pp. 367-375. Richardson, TX, USA: Society of Petroleum Engineers, Inc.

Lu, N. \& Likos, W. J. (2006). Suction stress characteristic curve for unsaturated soil. J. Geotech. Geoenviron. Engng 132, No. 2, $131-142$.

Ma, T. T., Wei, C. F., Xia, X. L. \& Chen, P. (2016). Constitutive model of unsaturated soils considering the effect of intergranular physicochemical forces. J. Engng Mech. 142, No. 11, 04016088 , https://doi.org/10.1061/(ASCE)EM.1943-7889.0001146.

Madland, M. V., Finsnes, A., Alkafadgi, A., Risnes, R. \& Austad, T. (2006). The influence of $\mathrm{CO}_{2}$ gas and carbonate water on the mechanical stability of chalk. J. Petrol. Sci. Engng 51, No. 3, $149-168$.

Megawati, M., Hiorth, A. \& Madland, M. V. (2013). The impact of surface charge on the mechanical behavior of high-porosity chalk. Rock Mech. Rock Engng 46, No. 5, 1073-1090.

Mitchell, J. K. \& Soga, K. (2005). Fundamentals of soil behavior, 3rd edn. New York, NY, USA: John Wiley \& Sons, Inc.

Newman, G. H. (1983). The effect of water chemistry on the laboratory compression and permeability characteristics of some North Sea chalks. J. Petrol. Technol. 35, No. 5, 976-980.

Nitao, J. J. \& Bear, J. (1996). Potentials and their role in transport in porous media. Water Resour. Res. 32, No. 2, 225-250.

Omdal, E., Madland, M. V., Kristiansen, T. G., Nagel, N. B., Korsnes, R. I. \& Hiorth, A. (2010). Deformation behavior of chalk studied close to in situ reservoir conditions. Rock Mech. Rock Engng 43, No. 5, 557-580.

Papamichos, E., Brignoli, M. \& Santarelli, F. (1997). An experimental and theoretical study of a partially saturated collapsible rock. Mech. Cohesive-Frictional Mater. 2, No. 3, 251-278.

Risnes, R. \& Flaageng, O. (1999). Mechanical properties of chalk with emphasis on chalk-fluid interactions and micromechanical aspects. Oil Gas Sci. Technol. 54, No. 6, 751-758.

Risnes, R., Haghighi, H., Korsnes, R. I. \& Natvik, O. (2003) Chalk-fluid interactions with glycol and brines. Tectonophysics 370, No. 1-4, 213-226.

Risnes, R., Madland, M., Hole, M. \& Kwabiah, N. K. (2005). Water weakening of chalk - mechanical effects of water-glycol mixtures. J. Petrol. Sci. Engng 48, No. 1, 21-36.

Roscoe, K. H. \& Burland, J. B. (1968). On the generalized stress-strain behavior of wet clays. In Engineering plasticity (eds J. F. Heyman and F. A. Leckie), pp. 535-609. Cambridge, UK: Cambridge University Press.

Schroeder, C. \& Shao, J. F. (1996). Plastic deformations and capillary effects in chalks. Proceedings of the 5th North Sea chalk symposium, Reims, France.

Schroeder, C., Bois, A. P., Maury, V. \& Hallé, G. (1998). Water/chalk (or collapsible soil) interaction: part II. Results of tests performed in laboratory on Lixhe chalk to calibrate water/chalk models. In Rock mechanics in petroleum engineering: Eurock '98 proceedings, pp. 833-840. Richardson, TX, USA: Society of Petroleum Engineers, Inc.

Sridharan, A. \& Venkatappa Rao, G. (1973). Mechanisms controlling volume change of saturated clays and the role of the effective stress concept. Géotechnique 23, No. 3, 359-382, https://doi.org/ 10.1680/geot.1973.23.3.359.

Stumm, W. \& Moyan, J. (1981). Aquatic chemistry, an introduction. New York, NY, USA: John Wiley \& Sons, Inc.

Taibi, S., Duperret, A. \& Fleureau, J. M. (2009). The effect of suction on the hydro-mechanical behaviour of chalk rocks. Engng Geol. 106, No. 1, 40-50.

Talesnick, M., Hatzor, Y. \& Tsesarsky, M. (2001). The elastic deformability and strength of a high porosity, anisotropic chalk. Int. J. Rock Mech. Min. Sci. 38, No. 4, 543-555.

van Genuchten, M. T. (1980). A closed-form equation for predicting the hydraulic conductivity of unsaturated soils. Soil Sci. Soc. Am. J. 44, No. 5, 892-898.

Wei, C. F. (2014). A theoretical framework for modeling the chemomechanical behavior of unsaturated soils. Vadose Zone J. 13, No. 9, 1-21. 